Impact of food hazards in school meals on students' health, academic work and financeSenior High School students' report from Ashanti Region of Ghana

\footnotetext{
Ababio, P.F. ${ }^{\text {a,b}}$, Taylor K.D.A. ${ }^{a}$, Swainson, $M^{\mathrm{a}}$. and Daramola, B.A. ${ }^{\mathrm{a}}$

${ }^{a}$ University of Lincoln, College of Sciences, National Centre for Food Manufacturing, Park Road, Holbeach, Spalding PE12 7PT, UK

${ }^{\mathrm{b}}$ University of Education, Winneba, Kumasi Campus, Catering and Hospitality Department, Box 1277, Ghana ${ }^{2}$

(sampat34j@yahoo.co.uk / 07400006200)
} 
Highlights: Food Safety hazards and effect in schools- Ghanaian Senior High Schools students' report

1. Seventy seven percent (77 \%) of the sampled students ate school provided meals all or most of the time and $52 \%$ had experienced foodborne infections between 3 to 12 times per academic year.

2. Foodborne illness affected students both academically and financially as $12 \%$ of students spent more than 5 days off school when sick and $10 \%$ spent between GHC $30.00->50.00$ on medication.

3. A higher percentage of students who only sometimes ate school meals and supplemented with home meals, own stored food or bought from vendors on campus significantly $(\mathrm{p}<0.05)$ paid more or medication for FBD.

4. Food allergy and physical contaminants in food were predominant among hazards reported by students though poorly managed.

5. Effectively cleaned utensils, hand washing facilities with detergents in dining halls and kitchens and hot food were highly recommended GHPs by students. 
Key words: Food hazards, Foodborne diseases, School meals, Senior High Schools, Students

\section{Impact of food hazards in school meals on students' health, academic work and finance- Senior High School students' report from Ashanti Region of Ghana}

\section{Abstract}

The study investigated the types of food hazards, the incidences and effect of foodborne diseases (FBD) in Senior Secondary Schools in Ghana. A questionnaire was used to collect data from 180 boarding school level 1 and 2 students from 45 sampled public schools in the Ashanti Region of Ghana and analysed with SPSS Version 21. Stones and insects in food received the highest complaints alongside food allergy and intolerance. Out of 180 students, $51.7 \%$ had experienced FBD with $21.1 \%$ of these reporting to health centers within their 1-2 years in school. FBD incidence rate was 3-12 times per academic year and $12 \%$ of the students had been absent from active academic work for as long as 5 days due to FBD with $10 \%$ spending between GHC 30.00 - >50.00 on medication per each episode. Students recommended improved GHP including standard cleaning procedures, food temperature control, available hand washing facilities with detergents at the dining halls and kitchens. Mandatory requirement of routine hygiene and food safety training for food handlers was required in schools with heightened monitoring, surveillance and law enforcement on acceptable practices. Supplier control across the food chain to reduce physical and chemical contaminants in agro products and food vendor's access control was required. Improving the quality and variety of school meals could also reduce dependence on other sources for food and help in controlling food safety risks. There was a need to increase awareness on the appropriate channels to report FBD incidence in schools for effective control measures and infection treatment. 


\section{Introduction}

30

31

32

The provision of safe food for children and adolescents of school going age is of great concern to governments and other stake holders as it improves health, growth and development of beneficiaries and encourages continued education in developing countries (Santana et al 2009, Oranusi et al, 2007, Afoakwa, 2005 and WHO, 2002). In Brazil approximately 37 million children from state elementary and middle schools are covered by the National School Feeding programme (Santana et al, 2009). In Italy, the estimated number of children benefiting from state school catering services is 2,700,000 (Marzano and Balzaretti, 2013), in Wales 77,627 pupils out of 495,000 are entitled to free school meals and the aim is to provide best health care possible through the provision of safe drinking water and adequate and nutritious meals in a safe environment (Meldrum et al 2009). The National school feeding scheme in South Africa equally aims at alleviating poverty and to improve learning capacity of children (Nhlapo et al, 2014). Whilst an estimated 1,000,000 pupils in basic education from poorest areas in Ghana are given one hot meal (lunch) per day in school through the Ghana School Feeding Programme (GSFP) to supplement breakfast and dinner from home, boarding students from Senior High Schools (SHS) in the country are given three (3) square meals per day in school. SHS students thus highly depend on school communal feeding programmes for their growth, wellbeing and general healthy lifestyle (Afoakwa, 2005). These good intentions by the government and stakeholders are challenged with increasing foodborne infection report from schools.

Foodborne diseases (FBD), an outcome of poor hygiene practices (Dablool et al 2014, Sumner et al, 2011, Panisello et al, 2000) are reported internationally in schools which tends to defeat the aims of quality food provision. The confined nature of the school environment favours direct transmission of diseases among individuals and may last for up to 3 to 5 days 
54 (Nhlapo et al 2014). This interrupts education and affects growth and development with persistent occurrence in children (Rodriguez-Caturla et al 2012). In Korea, 47\% of the cases of FBD were from schools (Ryu et al, 2011). In Japan within seven months in the year 1996, 11,826 cases with 12 deaths from $E$. coli 0157 : H7 infection were reported in schools, whilst in Brazil 11.6\% of documented FBD in 2005 were from school catering services (Santana et al 2009). School children (157) in South Wales experienced Escherichia coli O157 outbreak in 2005 due to cooked sliced meats supplied to schools (Meldrum et al 2009). In the year 2010, 544 adolescents had Salmonella food poisoning in France whilst 11,200 students in Germany from several hundreds of schools were affected with norovirus in the year 2012 (Marzona and Balzeratti 2013). Although the Ministry of Health (MoH) in Ghana reported that 1,348 children suffered from food poisoning in schools in Accra the Regional capital alone in the year 2007 (MoH, 2007), there is low reporting culture (WHO, 2009 and 2012) and lack of information from the other regions. Malm et al (2015) however reported that food storage facilities in the affected schools were poor and there was lack of protocols to avoid FBD from reoccurring in the schools in Ghana. Food poisoning reports are mainly from the media in Ghana and these have predominantly occurred in secondary schools (Ababio and Lovat, 2015). Foodborne diseases in Ghana were generally reported to have killed 90,692 people with 297,104 reported cases at Outpatient departments in hospitals costing the government GHC 594,208.00 and approximately 594,279 productive days in 2006 (OdameDarkwa, 2008). The Ministry of Food and Agriculture and World Bank (2007) also indicated that 1 in every 40 Ghanaians suffer serious FBD annually. The Food and Agriculture Organisation/World Health Organisation (2005) reported in 2005 that microbiological contaminants were the predominant hazard in street foods in Ghana and food vendors in the Ashanti Region are reported to be carriers of the enteric pathogen, Salmonella (Feglo and Sakyi, 2012) with most consumers not associating poor food hygiene with diseases 
79 (Tomlins et al 2002). The types of food hazards and their effect in schools in Ghana are not known, physical contaminants and chemical hazards are not reported in the country whilst

81 peanuts and pineapples alone have been reported to be sources of allergy in children between

82 the ages of 5 and 16 years in the country (Obeng et al 2011 and Boye, 2012).

83 School feeding services in SHS are managed by the schools established catering system 84 comprising of a domestic bursar (senior matron), a group of assistant matrons, cooks and 85 pantry men and a procurement unit. The state agencies in charge of surveillance and monitoring include the Food and Drugs Authority and the Environmental Health Protection units of the Metropolitan, Municipal and District Assemblies in Ghana. The primary hygiene standard being Codex Alimentarius hygiene requirements (WHO/FAO, 2009). The School Health Education Programme (SHEP) Unit of the Ghana Education Service also foresee health and sanitation activities in schools (Ghana Education Service, 2012). However sanitation facilities are reported to be low in secondary school kitchens in the country and matrons are reported not to consider their practices to be of risk to students (Afoakwa, 2005). This lack of motivation to improve hygiene systems and practice indicates a probable week surveillance and law enforcement systems in the country as indicated by WHO (2012) and Dwonfour- Asare (2015). FBD in schools have been reported to be due to poor hygiene standards internationally (Nhlapo et al 2014, Sourou-Bankole et al 2012, Adolf and Azis, 2012, Marzona and Balzaretti 2012) and affect the health, academic performance, growth and future wellbeing of children and the research sought to investigate the types of hazards, incidences of foodborne diseases and impact of these on students in Ghana. This study will provide added information from institutional caterings in the country to available data from the commercial sector.

\section{Methodology}


103 Permission to visit the Senior High Schools (SHSs) in the Ashanti Region of Ghana was 104 sought from the Regional Education Director. This region is the highest populated region out 105 of the 10 in the country (Ghana Statistical Service, 2012) with the highest number of public 106 SHSs (Ministry of Education, 2009, Siaw and Nortey, 2011). SHS students enrolment as at $1072008 / 2009$ in the country was 490,334 with Ashanti Region alone taking 44.1\% of this 108 population. Ashanti Region is a central trading zone in the country with high number of food 109 handlers with low formal education and hygiene practices (Osei, 2010 and Feglo and Sakyi, 110 2012, Ababio and Adi, 2012). An approval letter was then taken to the institutional heads in 111 a randomly sampled $58(67 \%)$ of the 86 public SHSs listed in the Ghana Education Service

112 Directory of the region. Out of the 58 schools visited, $45(52 \%)$ were available for the 113 research between July and September 2013. One hundred and eighty (180) first and second 114 year students, four (4) from each school were selected through the permission of their 115 academic headmasters or domestic bursars for the survey. Third year (final years) students 116 had completed school and left and were not part of the study. Students were briefed on the 117 objective of the exercise and asked to complete a given questionnaire. Questionnaire included 118 questions on students' awareness of causes and symptoms of FBD, their sources of education 119 on FBD, their experience in school, source of confirmation of FBD and related impact if any, 120 types of food hazards and contaminants found during school meals, other sources of meals in 121 school, their recommendations on improvement of hygiene in school kitchens and student's 122 demographics. Data was analysed with descriptive statistic tools on SPSS version 21.

\section{3. Results and discussion}

\subsection{Students' demographics, food sources and food poisoning awareness}

125 Out of the 180 Senior High School students sampled from 45 schools, 46.1 were first years and $53.9 \%$ were in their second year. Almost all the students had food poisoning awareness 
127 (some knowledge of causes and symptoms) with the exception of 8 (4.5\%) who had no awareness or were not sure of what food poisoning was about.

Table 1. SHS students from Ashanti Region, sources of meals, dining hall attendance and food poisoning awareness

Approximately half $(50.5 \%)$ of the sampled students attended the dining hall for meals all the time whilst the rest attended most of the time or some of the time. Almost all students had other sources of meals that supplemented their regular dining hall meals. Only $3.9 \%$ depended wholly on school meals (Table 1). Other sources of meals in the schools included students own stored food (42.2\%), food vendors (37.8\%), ready to eat food from relatives on school visiting days (10.6\%) and shops (5.5\%). This could make the control of food safety in SHS difficult as according to Afoakwa (2005) some of these vendors were not registered and hence not screened or monitored. Students also lacked storage and heating facilities in their dormitories. More than half of the students sampled (52\%) reported to have experienced some form of foodborne infection within their 1 to 2 years in secondary school. In Indonesia, $98.3 \%$ of students sample reported of high incidence of FBD after eating meals in schools that charged no tuition fees and were rated as poor in hygiene whilst only $8.8 \%$ of students in a high tuition fee paying school with good hygiene rate by students reported likewise (Adolf and Azis 2012). Hygiene and sanitation practices of food handlers directly affect the food safety and health of consumers. There was therefore the need to increase measures that would help motivate kitchen matrons and staff and food vendors to improve food safety and hygiene standards in schools (Panisello et al 2000) to prevent eminent FBD outbreak.

3.1.1 Foodborne illness medium of education, rate of occurrence and management among students in SHS in Ashanti Region

From Table 2, students in both academic levels were aware of foodborne diseases and there was no significant difference between the two academic levels on awareness. Knowledge on FBD was gained from the media $(81.2 \%)$, books $(65 \%)$, parents $(38.3 \%)$, personal experience 
155 (25.4\%), a friend's experience in school (20.7\%), seminars (16.8\%), and a relation's experience $(15.9 \%)$. Thus the media (radio and television) in Ghana was the major source of FBD awareness education for students in SHS followed by reading materials and parents. Seventy five percent $(75 \%)$ of the students mentioned a combination of diarrhoea, stomach crumps, vomiting and fever as symptoms related to FBD. This was similar to the report from Indonesian schools in Adolf and Azis (2012) report although students in Indonesia added cough and headache. Those who had ever experienced foodborne illness in school in Ghana were more than half of the population sampled (51.7\%) although a higher percentage did selfconfirmation of the possible cause of their illness. This was contrary to Tomlins et al (2002) who reported that most consumers among 530 people sampled in Accra did not associate diseases with poor hygiene and unsafe food. The SHS students in Ashanti Region were well informed although only $40.8 \%$ (21.1\% of total) of those who reported to have suffered from FBD in school sought medical attention from doctors and nurses (Table 2).

Table 2 Foodborne disease rate of occurrence among academic levels and source of confirmation of related experience

Although the rate of foodborne illness was high (1 - 4 times per school term) in the schools, only $21.1 \%$ out of the $51.7 \%$ reported to have their foodborne illness confirmed by a recognised health official whilst $30.6 \%$ only blamed food they had eaten to be the cause of their illness. Report of FBD was low among the students in SHS in the Ashanti Region of Ghana as reported by WHO (2009) in Nigeria. This culture makes tracing of causes and effect of FBD and the making of decisions on the necessary precautions difficult. It also creates a false sense of safety thus leading to lack of motivation to improve on poor hygiene practices among food handlers and their managers (Panisello et al 2000). If the FBD incidence rate among secondary school students (adolescents) was this high (1-4 times in 3 months) then the situation among the vulnerable groups in the Ghanaian society; babies, pregnant women, the aged and immunocompromised could be worse considering the 
increasing reliance on places outside the home for meals (Tomlins et al, 2002 and DwonfourAsare 2015) and the reported substandard hygiene conditions prevailing (Feglo and Sakyi, 2012, Ababio and Adi, 2012). Those who had fallen sick during school term due to foodborne illness were significantly higher than those who had not and the rate of FBD occurrence was higher than the 1 in every 40 Ghanaians suffering from FBD annually in the country reported by Ministry of Food and Agriculture/World Bank (2007) and supports Afoakwa (2005) in Ghana and Sourou-Bankole et al (2012) from Benin who reported that students in boarding schools were subjected to unhygienic food due to poor sanitary conditions. Sumner et al (2011) reported of food handlers in the United States reporting to work with diarrhoae and vomiting symptoms due to the absence of policies for staff to absent themselves from work when sick. Without proper hygiene training and control, students could be subjected to unsafe food due to lack of similar food safety policies and awareness in the work place in Ghana. The abuse of food holding time and temperature after cooking and inadequate cleaning and disinfection of food contact surfaces in schools could also subject students to food safety risks as reported by Dablool et al (2014) and Marzano and Balzeratti 197 (2013) from Italian schools respectively.

\subsubsection{Sources of meals for students in SHS in Ashanti Region and food safety risks}

Most meals served in dining halls were cooked ready-to-eat meals that required hot holding temperature and time control for safety. Rice was the most popular meal among $58.2 \%$ of the 180 students sampled. Based on school menu, level of preference of school meals were in the sequence of jollof rice, waakye (rice with beans) and pepper source with fish, rice balls with groundnut soup, rice and tomato stew, rice with kontomire stew and rice with beans stew, followed by Gari and beans $(25.6 \%)$, kenkey with sardine and pepper sauce $(11.1 \%)$, Banku with okro stew or soup $(2.3 \%)$ and $0.6 \%$ for yam with vegetable stew. The rest were tom brown and rice pudding for breakfast. Thus rice related meals were the most popular 
meal among the students which required effective temperature control against Bacillus cereus food poisoning and multiplication of Staphylococcus aureus and other pathogens in food from poor handling and temperature abuse (Dablool et al, 2014, Malm et al 2015)). There were no fruits on the menu plans in all the schools visited with the exception of one, 211 supporting Afoakwa (2005) report on absence of fruits in SHS feeding plan. Although a higher percentage of students ate their 3 square meals from the school dining hall, they supplemented these with other sources of food (Table 1). This could be due to small portion sizes, dislike for a particular meal or lack of variety, absence of fruits and other allergy or intolerance issues (Fig. 2). In Korean schools Ryu et al (2011) reported of the provision of a variety of side dishes and desserts with the main meal in schools. This was not present in the schools in Ashanti Region. Thus these may be additional factors that encouraged the use of other sources for food including food vendors in the schools.

219 Students who bought food from vendors in their school had the highest report $(21.1 \%)$ on FBD experience in school. The highest source of alternative meal among students was their own stored food (42.2\%) kept in 'chop boxes' under ambient conditions. Comparatively a higher percentage of those who bought meals from vendors $(55.8 \%)$, those who ate meals brought in by visiting relatives $(68.6 \%)$ and those who totally depended on only school meals (75.9\%) had experienced FBD during their 1-2 years in Senior High School. School meals, food from vendors and home meals brought to students and those kept in their boxes could all be causing FBD in the schools and required control.

\subsection{Available food hazards in school meals and food allergy management}

Fig 1. Types of physical contaminants identified in school meals

A high level of students $(66.4 \%)$ complained of physical contaminants in school meals, followed by chemical contaminants and mould. Approximately $2 \%$ of students reported of mould on school meals. Although students reported of chemical contaminants in food or 
funny smell, names of chemicals were not given however kitchen matrons in a previous interview had complained of the agro chemicals in food with special reference to grains with pesticides and fresh vegetables from local suppliers.

Among the physical contaminants present in school meals in SHS in Ashanti Region, stones were the highest food hazard followed by insects, human hair and metallic substances (Fig. 1) mostly from sponges used in cleaning pots. This happens when there is lack of standard operating procedures and Good Hygiene Practices (GHPs) including supplier control, raw material specification, process control, integrated pest management and personal hygiene. These are demanded by Codex Alimentarius (WHO/FAO, 2009) for catering services and other food establishments and must be enforced in Ghana as a member country. This supports Ababio and Adi (2012) and Afoakwa's (2005) report on the absence of GHP's among food handlers in Kumasi Metropolis and lack of standard sanitary conditions in schools in Ghana respectively.

248 Food allergy and intolerance, another emerging food hazard was present in the schools 249 (Fig.2). Ghanaian students surveyed had some form of allergy or intolerance with foods including peanuts, eggs and milk, seafood, gluten, monosodium glutamate, and okro. The 'other' response included beans or cowpea. The rising cause of food allergy and its effect in

252 Ghana is not known but there is the need for control as some reactions could be fatal and the 253 report from students implied the existence among consumers was not restricted to pineapple and peanuts as indicated by Obeng et al (2011) and Boye, (2012).

Over half of the students sampled (56\%) who had a form of allergy or intolerance were more likely not to report when in school but would avoid such meals when prepared or served in

257 the dining hall. Of the $56 \%$ who had food allergy or intolerance, only $37 \%$ of these $(20.5 \%$ 
of total) had reported food allergy and only $24 \%$ were given a special diet that is $13 \%$ were not given any consideration from school kitchens. There was a significant difference between food allergy or intolerance level and forms of management in schools $(\mathrm{p}<0.05)$ although this did not significantly affect the level of attendance to dining hall among students. Food allergy and intolerance however could be contributing factors to infrequent dining hall attendance which constituted $25.4 \%$ of students sampled. The group of students who did not know if they had allergy problem or not but refused to take school meals or attend to the dining hall all the time could also be educated to make informed decisions. Improving on food quality and variety and provision of suitable meals for students with intolerance and allergy issues could help reduce the dependence on other sources of food including food vendors. This could help with effective control of food safety improvement strategies in schools by school matrons and managers.

Region

272 The benefits of providing meals to school going age children by administrators are to ensure 273 that students have good health and development and also to encourage continued education 274 (Santana et al, 2009, WHO, 2002, Oranusi et al, 2007, Nhlapo et al 2014). Foodborne illness causes economic loss to countries world over and Ghana is not an exception. FBD's during school term

From Table 3, 49.4\% of students sampled who experienced some form of foodborne illness spent at least a day to more than 5 days from school or active academic work. This supports the cost on productive days lost in Ghana due to FBD reported by Odame- Darkwa, (2008).

283 Considering the fact that $26 \%$ of the 180 students reported of $2-4$ episodes of FBD within a 284 term, that is to say 13 in every 50 SHS students in Ashanti Region experience between 3- 6 
cases per school academic year. This rate from SHS is high as compared to the 1 in every 40

286 Ghanaian suffering from FBD annually case reported by MoFA/WorldBank (2007) and

287 similar to the Indonesian report by Adolf and Azis (2012) who reported 118 out of 120

288 students from poor hygiene categorised school reported of experiencing FBD after meals.

289 This is a report from public schools with boarding facilities only and figures could be high if

290 private schools in the region were considered and could be even higher with the other regions

291 in the country considered. The seriousness of the disease if considered to determine how

292 long a student recovered from illness did not however have any significant effect on the level

293 of attendance to the dining hall for meals $(\mathrm{p}>0.05)$ as most students mostly depended on the

294 school dining hall for their meals. Sickness goes with spending as the sufferer would need medication, other health related investigation if available and attendance depending on the level of discomfort. Out of the 180 students sampled, $60.5 \%$ were sure to have spent some amount of money ranging from GHC 1.0 to more than GHC 50.0 on medication due to foodborne illness during school term. Thus between GHC 108.9 - > GHC 5,445.00 is spend on medication alone per term by $60.5 \%$ of students in SHS in Ashanti Region. Thus approximately, a sum of between GHC 324.00 - > GHC 16, 335.00 (87.5- > 4410.00 USD) is spent by $60.5 \%$ of students, their parents, schools and National Health Insurance on medication alone annually due to FBD. This supports Odame-Darkwa (2008) and MoFA/WorldBank (2007) report on cost of FBD in the country. As most meals served in the

304 schools visited were cooked ready to eat meals, the quality of raw materials, processing 305 procedures, food holding temperatures and time, kitchens utensils cleanliness and kitchen 306 staff hygiene could all affect the safety of the meals post processing and required monitoring 307 and improvement in hygiene. Those who reported to have taken medication for the treatment 308 of foodborne infections were more than the $21.1 \%$ who reported to have visited health 309 facilities (nurse and doctors) during their ailment. This could be one of the possible causes of 
310 low reporting culture of foodborne infections as consumers are able to access over the 311 counter drugs (OCD) for the treatment of infections (WHO, 2012). This could also lead to

312 abuse and antibiotic resistance in the Ghanaian population. A situation that is not helpful for 313 the need for proper surveillance and control to improve on food safety as a nation. There

314 was a significant difference $(p=0.01)$ between the level of attendance to dining hall for meals and the amount of money spent by students. Those who attended the dining hall all the time were more likely to spend less money on medication for FBD than those who went less

317 regularly. Other sources of meals could be subjecting students to more food safety risks.

318 This was equally reported by Adolf and Azis (2012) who recommended yearly education on

319 food safety practices for sellers of foods around school campuses and staff in school canteens in Indonesia. Cost on medication for students was borne either by parents (30.6\%), National Health Insurance (15.6\%), schools $(8.3 \%)$, the student $(7.2 \%)$ and other combinations of the above $(2.3 \%)$

\subsection{Recommended hygiene improvement suggested by students}

All the students responded on the affirmative on the need to improve food hygiene and kitchen hygiene practices in their schools. The listed GHP were potable water, hand washing facilities, an enclosed kitchen, pest control, hot food, clean utensils and protective clothing for kitchen staff. From Figure 3, clean utensils was the single most mentioned recommendation by $52.5 \%$ of the students. This was followed by the need for hand washing

330 facilities in both the kitchens and dining halls (44.5\%). Hot food was the next recommended 331 food hygiene practice by $33.3 \%$ of the students followed by portable drinking water (28.3\%). Pest control was next with $27.2 \%$ recommendations then enclosed kitchen (13.9\%) before protective uniforms for staff (10.9) and a combination of all the listed the listed GHP's (10.6\%). As a Codex member country the General Principles of Food Hygiene by Codex Alimentarius (WHO/FAO, 2009) is applicable to the food industry in Ghana. The basic GHP 
listed include facility design, process control, maintenance and sanitation, personal hygiene and training, transport control and information and consumer awareness. Hazard Analysis and Critical control Point is also recommended by the body for good practice. These if adhered to and regularly monitored by the relevant state agencies including Food and Drugs

340 Authority and Environmental and Health Protection Unites of individual Metropolis and

341 District Assemblies could help with effective food safety control in schools. The Schools

342 Health Protection Programme units of the Ghana Education Service could also include

343 kitchen matrons and staff in hygiene training and auditing to improve on food safety practices

344 as currently their mandate and focus has been on students and pupils below tertiary education

345 level only (Ghana Education Service, 2012).

346

347

348

349

350

351

352

353

354

355

356

357

358

359

360

361

\section{Fig. 3. SHS boarding students recommended improvements in GHP in school kitchens}

In Brazilian schools, Santana et al (2009) reported of poor temperature control in poor and medium hygiene category schools before GHP intervention which negatively affected the microbiological quality of food. They reported that even in the presence of regulations set by the Health and Surveillance Committee, food safety measures were inadequate in schools as schools did not take into consideration the specific sanitation requirements needed. Thus in the presence of low FBD reporting culture, weak surveillance and law enforcement there is low motivation on the part of food handlers and managers to operate according to appropriate standards (WHO, 2012, Dwonfour- Asare 2015). Meldrum et al (2009) reported of a relatively safer ready- to- eat meals in schools in Wales as there were no microbiologically unacceptable food. The schools in Wales had HACCP in place whilst in Korea, the microbiological quality of school meals sampled were reported not to be adequate to ensure food safety (Ryu et al, 2011) hence the high rate of FBD from schools in the country. Ryu et al (2011) recommended the introduction of HACCP to improve food safety in Korean schools. Food stored out of recommended storage temperature and time could encourage 
spoilage and growth of pathogenic microorganisms to cause disease. Nhlapo et al (2014) equally reported on the absence of readily available hand washing facilities for kitchen staff in South African schools which they reported hindered good hand hygiene practice. Poor personal hygiene among staff could affect food safety and Sourou- Bankole et al, (2012) from Benin reported of high level of microbiological contaminants on staff hands in schools presenting risk to students. Marzano and Balzeratti (2013) recommended HACCP in schools as it improved cleaning practices and staff hygiene in Italian schools which was absent in all schools visited in Ghana. Standard cleaning procedures with training, supervision and appropriate time schedules for entire kitchens and ancillary rooms was required to improve cleanliness in Ghana. Lack of properly designed kitchens causes the loss of access control to both unauthorised persons and animals with their related hazards to food. Thus most of the schools needed improvement even as suggested by the students. This goes to support the need for improved food safety management systems in our Senior High Schools as recommended by Afoakwa, (2005) in Ghana and Sourou Bankole et al, (2012) from Benin in order to provide safe food for students. The lack of motivation on the part of matrons and kitchen staff to improve hygiene practices with the illusion that current practices were not a risk to food safety as reported by Afoakwa (2005) could also be due to low foodborne disease reporting culture among students, lack of regular rigorous surveillance with weak law enforcement in institutional kitchens and lack of knowledge of food hygiene requirements in

381 the country and required improvement. A system to monitor and control the overall food 382 chain in the country from farm to form, including suppliers of raw materials to SHS was required.

\section{Conclusion}

385 Food safety report from the Senior High Schools in the Ashanti Region of Ghana as reported by students required improvement. Students in the secondary schools who were adolescents 
387 (14-18 years) could be exposed to food hazards that had both immediate and protracted health 388 consequences in their growing lives. There was the need for regular monitoring and 389 surveillance of school food services by the appropriate state agencies with heightened law 390 enforcement, increased reporting culture of FBDs among students to appropriate health 391 facilities for control, media coverage with further investigation on causes and effect, mandatory and regular hygiene and food safety training for matrons, kitchen staff and food vendors that commensurate with their activities, developed and documented standard operating procedures availability with improved hygiene practices (adequate cleaning and disinfection of food contact surfaces, food handlers infectious disease control and hand washing), supplier and raw material specification and control as part of GHP and financial investments in infrastructure and resources (hand washing basins and detergents with dryers in kitchens and toilets) to improve on the current conditions in the schools. Other sources of meals to students equally required control with special reference to food vendors who gain access to sell food in SHS in Ashanti Region of Ghana.

401 Acknowledgment

402 The researcher would want to thank her Employer University of Education Winneba, Ghana, 403 for funding this research and the Dean and staff of the National Centre for Food 404 Manufacturing-University of Lincoln UK for their supervision and support.

405

406

407

408

409

410

\section{References}

Ababio P.F. and Lovatt P. (2015) A review on food safety and food hygiene studies in Ghana. Food Control. 47 (2015) 92-97

Ababio, P. F. and Adi, D.D. (2012). Evaluating food safety practices among food handlers in the Kumasi Metropolis. Internet Journal of Food Safety. Vol 14, 2012, p 35-43 
411 Adolf, J.N.P. and Azis, B.S. (2012) Microbiological status of various foods served in 412 elementary school based on social economic status differences in Karawaci Region, 413 Tangerang District-Indonesia. International Food Research Journal. 19(1) 65-70.

414 Afoakwa, E.O. (2005) Enhancing the quality of school feeding programme in Ghana. "The 415 Global Child Nutrition Forum 2005, Baltimore, Maryland, USA. Available at 416 http://works.bepress.com/emmanueloheneafoakwa/40.

417 Boye, J. I. (2012) Food allergies in developing and emerging economies: need for 418 comprehensive data on prevalence rates. Clinical and Translational Allergy 2012, 2:25

419 Dablool, A.S., Fouad, M.A. and Mihdhir, A.A. (2014) The effect of method of cooking and 420 holding conditions on enterotoxin production by Staphylococcus aureus in two types of Saudi 421 rice. European Academic Research. Vol II, Issue 2

422 Dwumfour-Asare, B. (2015) Effect of local authorities' field monitoring visits on 423 awareness of regulation and hygiene practices among street food vendors: The case of two 424 district capitals in Ghana. Journal of Behavioral Health. Vol. 4 Issue 3

425 FAO/WHO (2005) Informal food distribution sector in Africa- Street foods, importance and 426 challenges. Harare- Zimbabwe: FAO/WHO

427 Feglo, P.K., and Sakyi, K. (2012). Bacterial contamination of street vending food in Kumasi, 428 Ghana. Journal of Medical and Biomedical Sciences. (2012) 1(1):1-8

429 Ghana Education Service (2012) Annual Report- School Health Education Programme Unit. 430 Available at www.washinschoolsmapping.com viewed 9/15/2015

431 Ghana Statistical Service (2012) 2010 Population censors. Ghana Statistical Service 432 Malm, K.L., Nyarko, K.M., Yawson, A.E., GOGO, B., Lawson, A. and Afari, E. (2015) 433 Foodborne illness among school children in Ga East, Accra. Ghana Medical Journal Vol. 49 434 Number 2 
435 Marzono M.A. and Balzaretti, C.M. (2013) Protecting child heath by preventing school436 related foodborne illnesses: microbiological risk assessment of hygiene practices, drinking 437 water and ready-to-eat foods in Italian kindergartens and schools. Food control 34(2013) $438 \quad 560-567$

439 Meldrum, R.J., Mannion, P.T. and Garside, J. (2009) Microbiological quality of Ready-to-Eat 440 food served in schools in Wales, United Kingdom. Journal of Food Protection. Vol 72, No 1 $197-201$

442 Ministry of Education (2009). Representation on basic statistics and planning parameters for 443 SHS in Ghana 2008/2009. www.ges.gov.gh. viewed 12/27/12.

444 Ministry of Food and Agriculture/World Bank (2007). Review of food safety in Ghana. $445 \quad$ www.worldbank.org. Viewed 14/10/12

446 Ministry of Health Ghana (2007) The Ghana Health Sector annual programme of work. 447 Ministry of Health. www.moh.gov.gh viewed 6/12/2013

448 Nhlapo, N., Lues, R.J.K. and Groenewald, W.H. (2014) Microbial counts of food contact 449 surfaces at schools depending on a feeding scheme. South African Journal of Science. $450 \quad 2012: 110(11 / 12)$

451 Obeng, B.B., Amoah A.S., Larbi, I.A, Yazdanbakhsh, M., Van Ree, R., Boakye D.A. and 452 Hargers, F.C. (2011) Food allergy in Ghanaian school children: data on sensitization and 453 reported food allergy. International Acrch Allergy Immunol 2011: 155(1): 63-73.

454 Odame-Darkwa J. (2008) Contaminated food killed 90,692 in Ghana- FDA report. Available 455 at www.mordenghana.com. Viewed 2/9/2015

456 Oranusi, S., Umoh, V.J. and Kwaja, J.K.P (2007) Energy intake and anthropometry: a case 457 study of families in Zaria, Nigeria. $A J B$ Vol 6(4) pp 459-464 
Osei, F.B. (2010) Spatial statistics of epidemic data: the case of cholera epidemiology in 459 Ghana. A dissertation to obtain the degree of doctor at the University of Twente. Available at www.itc.nl/library/papers_2010

461 Panisello, P.J., Rooney, R., Quantick, P.C., and Stanwell-Smith, R. (2000) Application of 462 foodborne disease outbreak data in the development and maintenance of HACCP systems. 463 International Journal of Food Microbiology. 59 221-234

464 Rodriquez-Caturla, M.Y., Valero, A., Carrasco, E., Posada, G.D., Garcia-Gimeno, R.M. and 465 Zurera, G. (2012) Evaluation of hygiene practices and microbiological status of ready to eat vegetable salads in Spanish school canteens. Journal of the Science of Food and Agriculture.

467 Vol. 92 Issue 11

468 Ryu, J., Ko, J., Park, H., Yang, S. and Kim, H. (2011) Microbiological examination of 469 nonheated foods served in feeding programmes of elementary schools, Iksan City, Jeonbuk Province, Korea. Journal of Food Protection. Vol 47 No. 9 1564-1568

471 Santana, N.G., Almeida, R.C.C., Ferreira, S.J., Almeida, F.P. (2009). Microbiological quality 472 and safety of meals served to children and adopted good manufacturing practices in public 473 school catering in Brazil. Food control 20 (2009) 255-261

474 Siaw, A.O. and Nortey, S. (2011) Teaching and learning of visual arts in SHS in Ghana. 475 Journal of Education and Practice. Vol 2 No 42011

476 Sourou-Bankole, S.H., Doujnon, T.J., Edorh, P.A., Dougnon, T.V., Legonou, M., Klotoe, J.R. 477 and Loko, F. (2012). Portage of bacteria responsible for foodborne illness in scholarly 478 canteens (Republic of Benin) Advances in microbiology. 2012, 2, 340-344.

479 Sumner, S., Brown, L.G., Frick, R., Stone, C., Carpenter, L.R., Bushnell, L., Nicholas, D., 480 Mark, J., Blade, H., Tobin-D'Angelo, M., Everstine, K. and the Environmental Health 481 Specialists network working group. (2011) Factors associated with food workers working 
482 while experiencing vomiting or diarrhoea. Journal of Food Protection. Vol 74. No 2 pages $483 \quad 215-220$

484 Tomlins, K., Johnson, P.N, Aseidu O.P., Myhara, B., Greenhalgh, P. (2002). Street food in 485 Ghana: a source of income, but not without hazards. Available at http:// 486 www.iita.org/info/phnews5/mr8.htm (Accessed on Jan. 32011

487 WHO (2002) Foodborne diseases, emerging. Fact Sheet No. 124

488 WHO (2009) Global burden of disease, WHO: Geneva 2009. In Ebenoso et al (2012)

489 Occurrence of Salmonella, Vibrio and E. coli in Edible land snail in Niger delta, Nigeria. 490 Journal of Microbiology, Biotechnology and Food Science. 2 (2) 610-618

491 WHO (2012) Manual for integrated foodborne disease surveillance in the WHO African 492 Region. WHO Regional Office for Africa. Brazzaville.

493 WHO/FAO (2009) Codex Alimentarius Commission - Food hygiene Basic text. $4^{\text {th }}$ Edition. $494 \mathrm{WHO} / \mathrm{FAO}$ 
Table 1 SHS students from Ashanti Region, sources of meals and food poisoning awareness

\begin{tabular}{c|l|l}
\hline Gender & Frequency & Percentages \\
Male & 88 & 48.9 \\
Female & 92 & 51.1 \\
\hline Academic level & & \\
First year & 83.0 & 46.1 \\
Second year & 97.0 & 53.9 \\
\hline Food poisoning Awareness & & \\
Yes & 172 & 95.5 \\
No & 7 & 3.9 \\
Not sure & 1 & 0.6 \\
\hline Altendance to dining hall for meals & & \\
Mostly & 91 & 50.5 \\
Sometimes & 48 & 26.7 \\
My own stored food & 41 & 22.8 \\
Food vendors in school & 76 & \\
Home meals & 68 & 32.2 \\
Shops & 19 & 10.6 \\
None & 10 & 5.5 \\
\hline Other sources of meals for students & 7 & 3.9 \\
\hline
\end{tabular}


Table 2. Foodborne illness rate of occurrence among academic levels and source of confirmation of related experience

\begin{tabular}{|c|c|c|c|c|c|c|}
\hline \multirow[b]{2}{*}{ Academic levels } & \multicolumn{5}{|c|}{ FDB awareness } & \multirow[b]{2}{*}{ Chi square } \\
\hline & Yes & No & Not sure & $\begin{array}{l}\text { No } \\
\text { response }\end{array}$ & Total & \\
\hline First year & 44.4 & 1.1 & 0.6 & 0.0 & 46.1 & $2.118(0.714)$ \\
\hline Second year & 51.1 & 2.8 & 0.0 & 0.0 & 53.9 & \\
\hline \multirow[b]{2}{*}{ Academic levels } & \multicolumn{5}{|c|}{ Rate of FBD occurrence per school term } & \\
\hline & Once & Twice & $\begin{array}{l}\text { Three to } \\
\text { Four } \\
\text { times }\end{array}$ & $\begin{array}{l}\text { Can't } \\
\text { remember } \\
+\mathrm{NA}\end{array}$ & Total & Chi square \\
\hline First year & 9.4 & 7.2 & 5.0 & 24.5 & 46.1 & $9.177(0.515)$ \\
\hline \multirow[t]{2}{*}{ Second year } & 12.2 & 9.4 & 3.9 & 28.4 & 53.9 & \\
\hline & \multicolumn{5}{|c|}{$\begin{array}{c}\text { Source of confirmation of related foodborne illness } \\
\text { experienced during school term }\end{array}$} & \\
\hline $\begin{array}{l}\text { Foodborne } \\
\text { illness } \\
\text { experienced in } \\
\text { School }\end{array}$ & $\begin{array}{l}\text { School } \\
\text { Nurse }\end{array}$ & $\begin{array}{l}\text { A } \\
\text { Doctor }\end{array}$ & $\begin{array}{l}\text { Personal } \\
\text { decision }\end{array}$ & $\begin{array}{l}\text { Not } \\
\text { Applicable }\end{array}$ & Total & Chi square \\
\hline Yes & 4.4 & 16.7 & 30.6 & 0 & 51.7 & $101.560(0.001)$ \\
\hline No & 2.8 & 6.1 & 7.8 & 31.7 & 48.4 & \\
\hline
\end{tabular}

NA $=$ Not applicable 
Table 3. Dining hall attendance and days and amount spent by students who suffered FBDs during school term

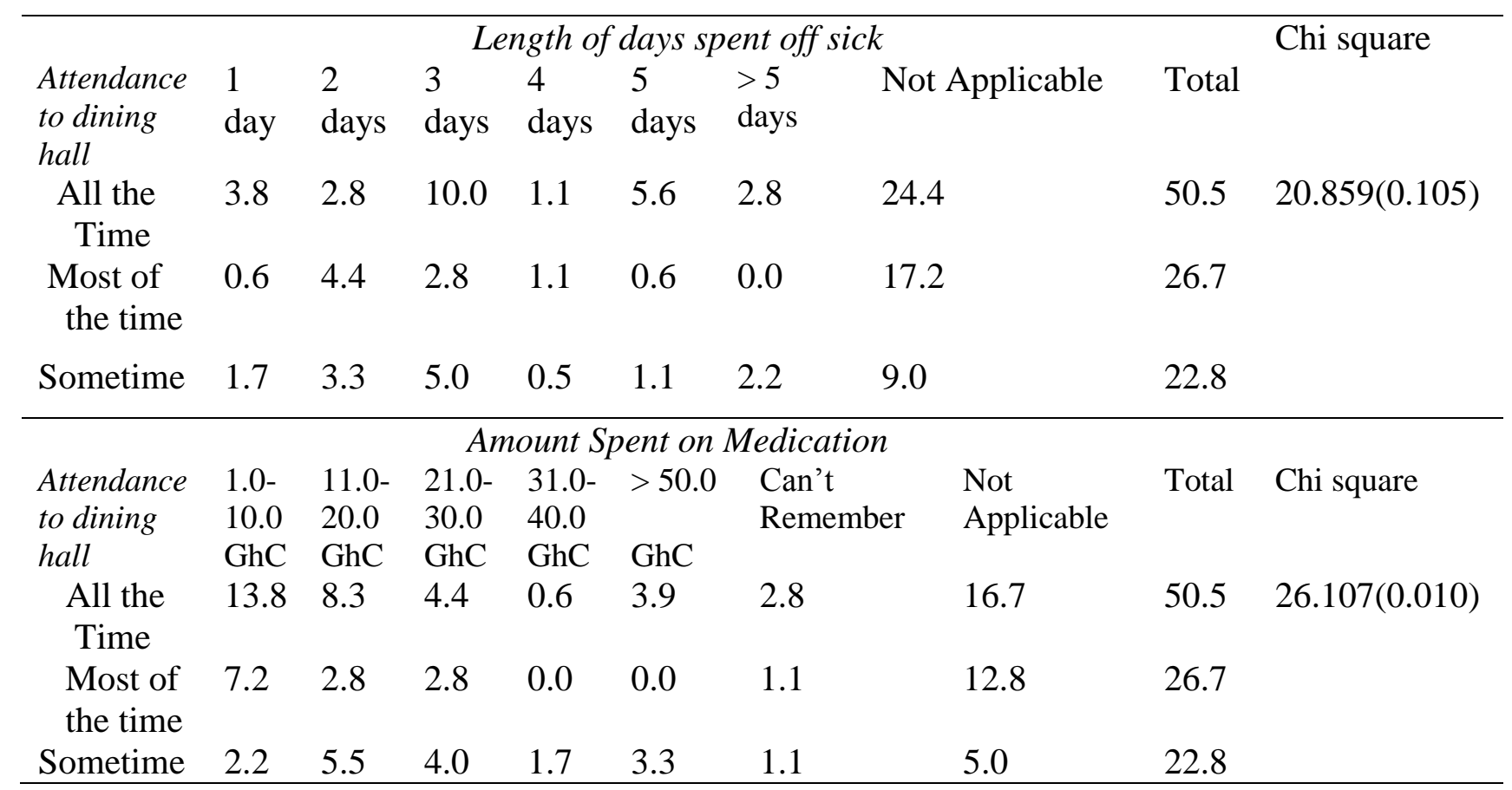

Possible use of over the counter drugs among students as percentage reporting at health centers, $21.1 \%$ (Table 2) was lower than those buying medication for infection treatment (60.5\% Table 3 ) 


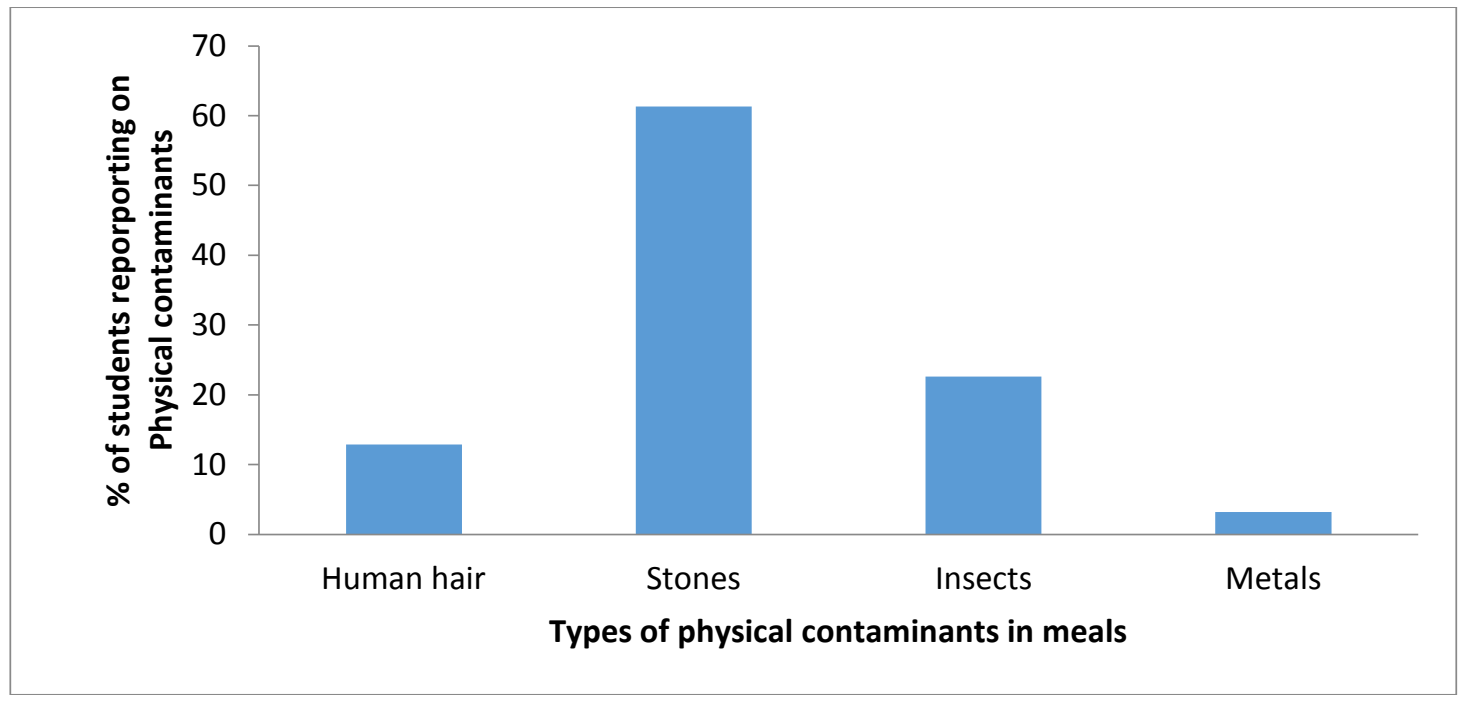

Figure 1. Percentage of students reporting types of physical contaminants in meals 


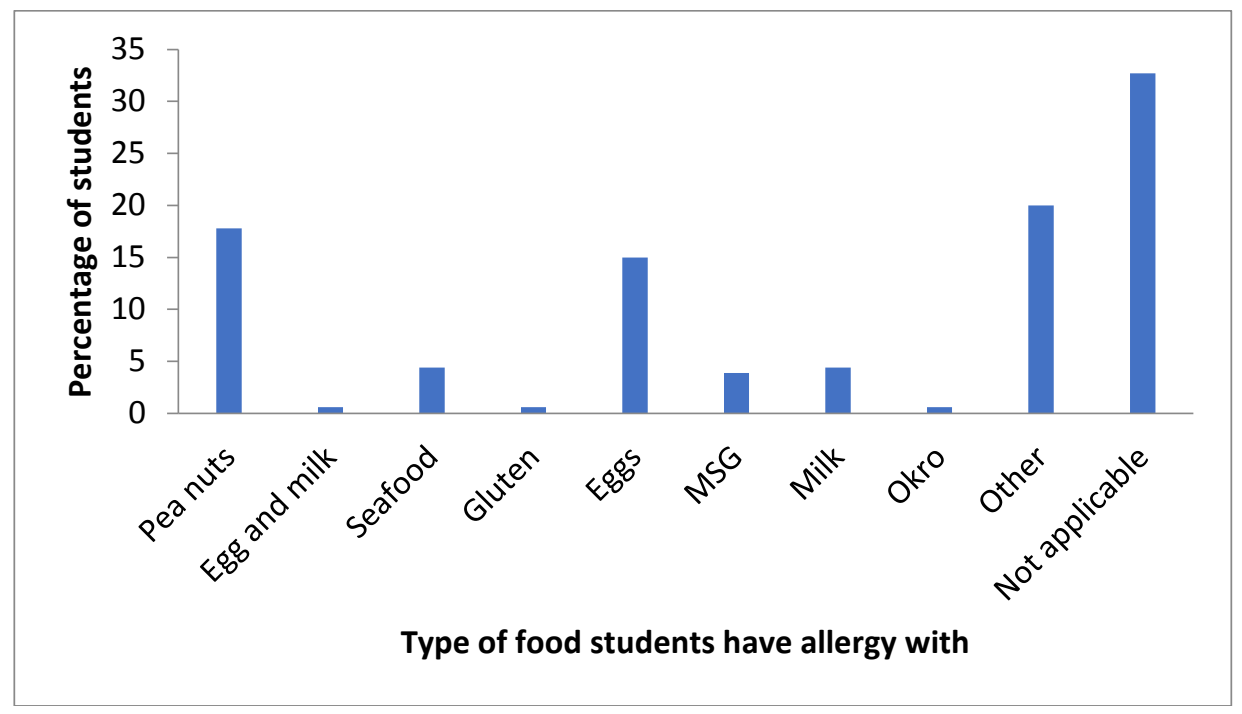

Fig. 2. Food that students have allergy /intolerance problems with 


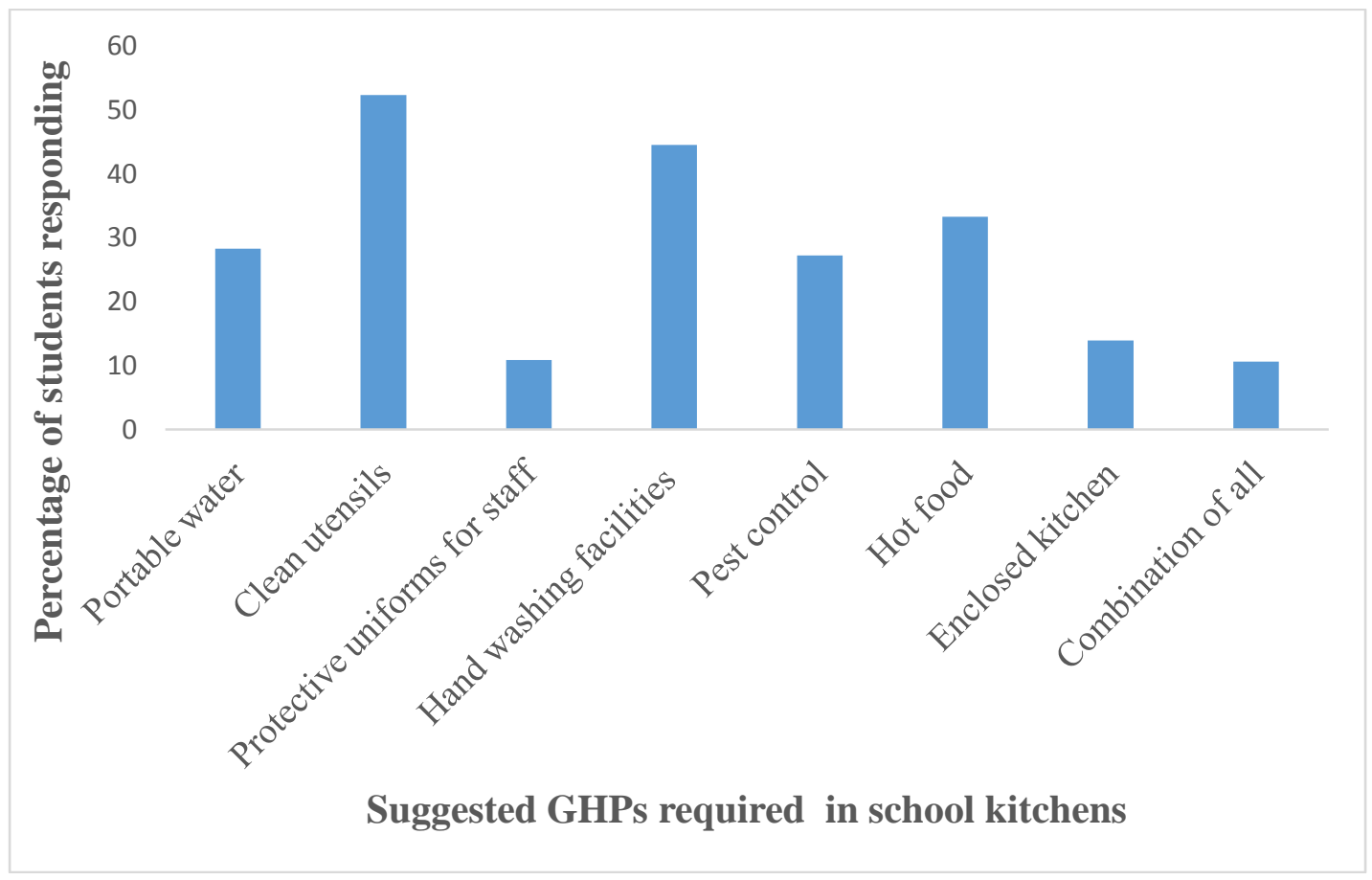

Fig. 3. SHS boarding students recommended improvements in GHP in school kitchens 